\title{
Paradoxical Reaction to Midazolam in Preterm Neonates: A Case Series
}

\author{
Mahendra Kumar Gupta, Jayashree A. Mondkar, Deepraj Hegde \\ Department of Neonatology, Lokmanya Tilak Municipal Medical College, Lokmanya Tilak Municipal General Hospital, Mumbai, Maharashtra, India
}

\section{Abstract}

Midazolam is a drug belonging to the benzodiazepine group and is used commonly for seizure control as well as preoperative and procedure-related sedation in neonates. Many adverse effects of midazolam have been reported in the past. Paradoxical stimulation of the central nervous system such as restlessness, nightmare, and hallucinations as well as hypomanic behavior has been reported in adults and children. Seizure is a rare adverse effect of midazolam. Cases of myoclonic movements associated with midazolam have been published worldwide; however, none so far have been reported from India. We report two newborns in our Neonatal Unit, who developed myoclonic seizure after the administration of midazolam. Both of these neonates were preterm, require multiple invasive and noninvasive investigations also leads to parent and clinician stress.

Keywords: Midazolam, neonatal period, seizures

\section{INTRODUCTION}

Midazolam is a drug belonging to the benzodiazepine group and is used commonly for seizure control as well as preoperative and procedure-related sedation in neonates. ${ }^{[1]}$ Many adverse effects of midazolam have been reported in the past. Paradoxical stimulation of the central nervous system such as restlessness, nightmare, and hallucinations as well as hypomanic behavior has been reported in adults and children. Seizure is a rare adverse effect of midazolam. ${ }^{[2,3]}$ Cases of myoclonic movements associated with midazolam have been published worldwide; however, none so far have been reported from India. We report two newborns in our Neonatal Unit, who developed myoclonic seizure after the administration of midazolam. This less common adverse effect with significant clinical implications needs to be brought to the notice of practicing neonatologist worldwide.

\section{Case Reports}

\section{Case 1}

An inborn preterm 34 weeker male neonate, weighing $1960 \mathrm{~g}$, a product of non-consanguineous marriage, born

\begin{tabular}{|l|l|}
\hline \multicolumn{3}{c|}{ Access this article online } \\
\hline Quick Response Code: & Website: \\
& www.ijccm.org \\
\cline { 2 - 2 } & \\
&
\end{tabular}

to a primigravida mother, was shifted to the Neonatal Intensive Care Unit (NICU) for respiratory distress. A diagnosis of early-onset sepsis with congenital pneumonia was made as per chest X-ray report and a significant history of prelabour premature rupture of membrane so that empirical antibiotics could be started. By $48 \mathrm{~h}$ of life, the baby became lethargic and developed generalized edema. Pseudomonas was grown in blood culture and a cerebrospinal fluid (CSF) examination done was suggestive of meningitis. Sensorium and activity improved following upgradation of antibiotic therapy as per the blood culture report. A magnetic resonance imaging (MRI) of the brain was planned in view of hyperechoic ventricle on cranial ultrasound. The baby had an episode of myoclonic seizures in the MRI room only after receiving of injection midazolam $0.1 \mathrm{mg} / \mathrm{kg}$ for sedation first time. The procedure was deferred and workup for seizure etiology was carried out such as septic, metabolic,

Address for correspondence: Dr. Mahendra Kumar Gupta, Department of Neonatology, Lokmanya Tilak Municipal Medical College, Lokmanya Tilak Municipal General Hospital, Sion (West), Mumbai - 400 022, Maharashtra, India. E-mail: mkgupta.nhrc@gmail.com

This is an open access journal, and articles are distributed under the terms of the Creative Commons Attribution-NonCommercial-ShareAlike 4.0 License, which allows others to remix, tweak, and build upon the work non-commercially, as long as appropriate credit is given and the new creations are licensed under the identical terms.

For reprints contact: reprints@medknow.com

How to cite this article: Gupta MK, Mondkar JA, Hegde D. Paradoxical reaction to midazolam in preterm neonates: A case series. Indian J Crit Care Med 2018;22:300-2. 
repeat Ultra sonography (USG) brain, and inborn errors were normal. The baby again had myoclonic seizures during lumbar puncture as midazolam was given before the procedure and managed by intravenous phenobarbitone and levetiracetam 20 and $10 \mathrm{mg} / \mathrm{kg}$, respectively. The baby condition improves over the next $48 \mathrm{~h}$ and began breastfeeding. On review, injection midazolam was found to be a culprit of myoclonic seizures. The temporal association between midazolam administration and the occurrence of neonatal seizures became evident. The further hospital course was uneventful. Electroencephalogram (EEG) was done 4 days later to the last episode of seizure, showing continuity and synchronicity of background activity present during active sleep and awake state, intermittent beta and theta waves on trace, no sharp wave and spike was noted during the trace. MRI brain was reported normal. Antiepileptic drugs (AEDs) were stopped before discharge. The infant was followed up for 9 months. No seizures and neurodevelopment deficits were documented in follow-up examination.

\section{Case 2}

An inborn preterm male neonate, born to a primigravida short-stature mother by gestation, 33 weeks of age, weighing $1350 \mathrm{~g}$, was admitted to the NICU for very low birth weight care. The baby was hemodynamically stable with Silverman-Anderson Score of 0/10 and was started on full orogastric tube feed of bank milk. On day 4 of life, the baby was on full oral bank milk feed. He regains his birth weight by the day of life 11. As per protocol screening, head ultrasound was done and founded germinal matrix cyst of $3 \mathrm{~mm}$ diameter, although the baby was asymptomatic and gaining weight and no sign of neurological dysfunction occipitofrontal circumference was normal and increment was also normal. Repeat USG head done at 16 days of life, suggestive of germinolytic cyst of $7 \mathrm{~mm}$ in diameter, but the baby was asymptomatic, no neurological dysfunction with normal physical growth. Computed tomography (CT) brain planed for increasing cyst, 2 days later baby went for CT, and has convulsion only after giving midazolam $(0.1 \mathrm{mg} /$ $\mathrm{kg}$ ) for sedation so the procedure was withheld. Convulsion was of generalized myoclonic in nature last for $6 \mathrm{~min}$. The baby made nothing per oral for $2 \mathrm{~h}$, and all metabolic, septic (CSF) workups done were reported normal. CT head and EEG done 5 days later to the episode of seizure, were reported normal. No AED was started for convulsion because the baby did not encounter another episode of convulsion and suspecting midazolam-induced myoclonic seizure. On day $23^{\text {rd }}$, the baby was discharged; no convulsion and neurological abnormality were noticed during follow-up examination for 6 months.

\section{DISCUSSION}

Midazolam is widely used in the NICU for seizure control and before procedures to alleviate stress and pain. It has fast onset and short duration of action. However, a paradoxical reaction such as myoclonic movements is a rare adverse effect. We report two neonates who developed epileptic manifestations a few seconds after the bolus administration of intravenous midazolam. Other possible causes of seizures were ruled out by appropriate investigations. We attributed the seizures to injection midazolam since this type A class of adverse drug reaction was evaluated for causality and was found to have a probable/likely causal relationship with midazolam as per Naranjo algorithm. ${ }^{[4]}$ Beyza Ozcan et al., Marium M adams et al. and Van den Anker JN et al. reported myoclonic movements in one, eleven and four premature neonates respectively, where as Maria Augusta Montenegro et al reported multi focal clonic movements in four preterm neonates after they received a slow bolus administration of $0.1 \mathrm{mg} / \mathrm{kg}$ of midazolam for sedation. ${ }^{[5-8]}$ Although most of the reported cases involved preterm neonates, Zaw et al. described three cases of midazolam-induced, myoclonic-like abnormal movements in term infants, and flumazenil was used to reverse it in one of the case. ${ }^{[5]}$ In our case, the seizure movements responded to AEDs was also reported by Marium $\mathrm{M}$ adams et al. and Van den Anker JN et al. ${ }^{[6,7]}$

The postictal EEG did not show any abnormality. Most of the previously reported case series also did not report EEG abnormality. ${ }^{[9]} \mathrm{We}$, hence, stopped all AEDs before discharge from the hospital and no neurodevelopmental abnormality were founded on follow-up.

Midazolam acts by binding to gamma-aminobutyric acid A (GABA-A) receptors. There is a limited synthesis of GABA in the newborn cortex. It is probable that imbalance of GABA subunit (agonist) and benzodiazepine subunit (modulators) with longer half-lives $(6.25 \mathrm{~h})$ of midazolam creates an excitatory influence, thereby causing the seizure-like activity. ${ }^{[2]}$

\section{Declaration of patient consent}

The authors certify that they have obtained all appropriate patient consent forms. In the form the patient(s) has/have given his/her/their consent for his/her/their images and other clinical information to be reported in the journal. The patients understand that their names and initials will not be published and due efforts will be made to conceal their identity, but anonymity cannot be guaranteed.

\section{Financial support and sponsorship}

Nil.

\section{Conflicts of interest}

There are no conflicts of interest.

\section{ReFERENCES}

1. Walter-Nicolet E, Annequin D, Biran V, Mitanchez D, Tourniaire B. Pain management in newborns: From prevention to treatment. Paediatr Drugs 2010;12:353-65.

2. Mancuso CE, Tanzi MG, Gabay M. Paradoxical reactions to benzodiazepines: Literature review and treatment options. Pharmacotherapy 2004;24:1177-85.

3. Pacifici GM. Clinical pharmacology of midazolam in neonates and children: Effect of disease-a review. Int J Pediatr 2014;2014:309342. 
4. Zaki SA. Adverse drug reaction and causality assessment scales. Lung India 2011;28:152-3.

5. Ozcan B, Kavurt S, Yucel H, Bas AY, Demirel N. Rhythmic myoclonic jerking induced by midazolam in a preterm infant. Pediatr Neurol 2015;52:e9.

6. Montenegro MA, Guerreiro MM, Caldas JP, Moura-Ribeiro MV, Guerreiro CA. Epileptic manifestations induced by midazolam in the neonatal period. Arq Neuropsiquiatr 2001;59:242-3.
7. Adams MM, Hahn JS, Benitz WE. A series of neonatal patients with paradoxical seizures like reaction to bolus intravenous injection of midazolam. Pediatr Res 1997:41:134.

8. van den Anker JN, Sauer PJ. The use of midazolam in the preterm neonate. Eur J Pediatr 1992;151:152.

9. Zaw W, Knoppert DC, da Silva O. Flumazenil's reversal of myocloniclike movements associated with midazolam in term newborns. Pharmacotherapy 2001;21:642-6. 